\title{
Unresolved Bereavement and Other Mental Health Problems in Parents of the Sewol Ferry Accident after 18 Months
}

\author{
Hyu Jung Huh', Seung Huh², So Hee Lee ${ }^{3}$, and Jeong-Ho Chae ${ }^{2 凶}$ \\ ${ }^{1}$ Stress Clinic, Health Promotion Center, Seoul St. Mary's Hospital, The Catholic University of Korea College of Medicine, Seoul, Republic of Korea \\ ${ }^{2}$ Department of Psychiatry, Seoul St. Mary's Hospital, The Catholic University of Korea College of Medicine, Seoul, Republic of Korea \\ ${ }^{3}$ Department of Psychiatry, National Medical Center, Seoul, Republic of Korea
}

\begin{abstract}
Objective This study examined the overall mental health consequences of the bereaved parents after the Sewol ferry accident.
Methods Eighty-four bereaved parents participated in the study. Self-report scales assessing the severity of psychiatric symptoms and other related psychosomatic problems were used at 18 months following the accident. Univariate descriptive statistics and regression analyses were performed to report the prevalence, severity, and correlates of psychiatric symptoms.

Results $94 \%$ of the participants appeared to suffer from complicated grief based on scores on the Inventory of Complicated Grief (ICG). Half of the participants were categorized as having severe depression and $70.2 \%$ reported clinically significant post-traumatic symptoms according to scores on the Patient Health Questionnaire-9 (PHQ-9) and PTSD Check List-5 (PCL-5). No significant differences by gender were observed in the severity of psychiatric symptoms. A higher educational level was associated with more severe psychiatric symptoms in fathers.

Conclusion The loss of a child due to a disaster caused by human error may continue to have a substantial impact on parental mental health at 18 months after the event. A longitudinal study following parents' mental health state would be necessary to investigate the longterm effects of the traumatic experience in the future.

Psychiatry Investig 2017;14(3):231-239
\end{abstract}

Key Words Bereavement, Disaster, Complicated grief.

\section{INTRODUCTION}

On April 16, 2014, a 6,825-ton motor vessel, the Sewol ferry, sunk in the sea of Jeollanam-do, South Korea. In all, 304 of the total 476 passengers and crew members died in the disaster. A total of 339 of the passengers were sophomore students and teachers of Danwon High School in Ansan city, Gyeongi-do, on a field trip. In this accident, 261 students and teachers from the high school died. ${ }^{1}$

The Korean Coast Guard concluded that an "unreasonably sudden turn" to starboard was the primary cause of the capsizing. ${ }^{2}$ According to the Coast Guard, the sudden turn caused the cargo to shift to port, causing the ship to list and to even-

Received: October 17, 2016 Revised: January 17, 2017

Accepted: January 29, 2017 Available online: February 27, 2017

$\bowtie$ Correspondence: Jeong-Ho Chae, MD, PhD

Department of Psychiatry, Seoul St. Mary's Hospital, The Catholic University of Korea College of Medicine, 222 Banpo-daero, Seocho-gu, Seoul 06591, Republic of Korea

Tel: +82-2-2258-6083, Fax: +82-2-2258-3870, E-mail: alberto@catholic.ac.kr

(c) This is an Open Access article distributed under the terms of the Creative Commons Attribution Non-Commercial License (http://creativecommons.org/licenses/by$\mathrm{nc} / 4.0$ ) which permits unrestricted non-commercial use, distribution, and reproduction in any medium, provided the original work is properly cited. tually become unmanageable for the crew. ${ }^{2}$ Overloading and not properly securing cargo were also seen as direct causes of the sinking. ${ }^{3}$ As the ship capsized, the ferry began an announcement ordering the passengers to stay put, alerting them that moving was dangerous and this announcement continued even when water began flooding the cabins. ${ }^{4}$ Furthermore, the captain had abandoned the ship with passengers still aboard the ferry.

The sinking of this ship has resulted in widespread social and political reaction within South Korea. Many have criticized the actions of the captain and most of the crew of the ferry who escaped without any rescue activities for the passengers. Many more have criticized the ferry operator and the regulators who oversaw its operations. ${ }^{5}$ Additional criticism has been directed at the South Korean government and media for its disaster response and attempts to downplay government culpability. ${ }^{6}$ One month after the disaster, the captain and three crew members were charged with murder, while the other 11 members of the crew were indicted for abandoning the ship. ${ }^{6}$

During the capsizing and the subsequent reporting, the gov- 
ernment's announcements, as well as the media, were inconsistent and inaccurate. ${ }^{7}$ About two hours after the accident, the media began reporting that all students had been rescued, but shortly after, they reported that 174 people had been rescued, 4 had died, and 84 were missing. ${ }^{8}$ Many newspapers had to make corrections and apologize for their earlier reports. ${ }^{9}$

Conspiracy theories and rumors spread quickly. ${ }^{10}$ Mistrust, paranoia, and anger about the government and the society at large became endemic. Thousands of demonstrators, including the bereaved family members of the victims, demanded a further investigation into the cause of the disaster in the center of the capital city of Korea. ${ }^{11}$ The bereaved families continued to protest and called for the establishment of an independent committee for investigation into the government's responsibility for the sinking for over one year. ${ }^{12}$ The families showed deep rage at the government's action at the first anniversary of the accident through the media. Yearlong investigations have suggested that the disaster was avoidable and that it was the result of corporate greed and a lax government. ${ }^{13}$

Considering psychological shock and possible mental health problems of bereaved families and survivors, the government and mental health professionals had tried various types of national or community undertakings for psychological support. From April 16 to 30, 2014, the mental health centers of Gyeonggi-do and Ansan city cooperated to develop a temporary organization called Gyeonggi-do-Ansan city Combined Disaster Psychological Support Group, which provided emergency psychological services for the psychological trauma and mourning process of the bereaved families of the dead and missing. ${ }^{1}$ They provide counseling for mourning, medical activity and 24 hour hotline for high risk group near the incense altars and funeral halls. A counseling center for Ansan and Gyeonggi-do residents experiencing indirect trauma was managed and volunteers with various professional background were educated and integrated into the system.

Finally Ansan mental health trauma center was newly established for long term mental health care of the bereaved families. The center consists of 35 people including psychiatrists, clinical psychologists, mental health social workers, mental health nurses, general social workers, and general administration employee. ${ }^{1}$ The family psychological support team for bereaved adult family members had case managers for each family unit, who contacted subjects through funeral hall, house, place of activity, and trauma center visits to provide potential services. External psychological counseling experts were placed in class self-help gatherings for each grade. Various programs were run, such as group methods, yoga, healing composition, meditation, self-help gatherings, art programs, mind and body stabilization methods, bio-feedback, and EMDR. People often complained of physical pain related to their mental pain, so physical methods for mind and body stabilization were mainly provided. Psychiatrists were available for continuous evaluations and counseling for the bereaved families. Regular and continuous case management was continued. Customized services that reflected individual needs, and active crisis intervention were provided to the bereaved families and local residents with a psychological support system by house visits, telephone management, and trauma center visits. In addition, an expert service based on mourning-based case management was provided, and various resources were cultivated in local society to provide related integrated services.

Although a lot of attempt and endeavor to help and support the bereaved families were continued, any systemized investigation about mental health state of the bereaved parents could not perform due to the difficulty of getting consent of the bereaved parents for 1 year due to social and political issue. Most bereaved parents became furious and mistrusted the government and the society at large. They also suffered from excessive media attention and stigma. For these reasons, the bereaved parents resisted participating in any other investigation, especially about their mental health, for more thanone year after the disaster.

Various types of disasters can adversely affect mental health. A large body of research has demonstrated that various traumatic experiences such as physical injury, a property loss or loss of loved one originate from disasters and are related to significant psychological difficulties for many people. ${ }^{14-17}$ In the case of the Sewol ferry accident, traumatic grief was one of the most important issues for the parents of the dead students. Some epidemiological studies have found that a sudden, unexpected loss of a loved one is one of the most common life stressors leading to post-traumatic stress disorder (PTSD). ${ }^{18-21}$ However, the mental health consequences of traumatic loss are still unclear. In addition, the benefits of various psychological interventions from the mental health care service system are unknown.

The present study was the first attempt to investigate the current mental health state of the bereaved parents. The aim of the study was to 1) estimate the prevalence of mental health problems and other related psychosomatic problems of the bereaved parents of the Sewol ferry accident after 18 months, 2) examine the association among demographic factors and, current mental health state, and 3) investigate differences in psychiatric symptoms by gender.

\section{METHODS}

\section{Participants and procedure}

Before launching the study, researchers contacted the rep- 
resentatives of the bereaved families to explain the purpose of the study. After obtaining agreement of the representatives of the bereaved families for the study, participants were recruited with cooperation from the Ansan mental health trauma center. The center contacted with 516 bereaved parents (father: 236 and mother: 280) asked them about intention of the study participation. Among them, a total of 84 bereaved parents who agreed with participation were included in the present study. The schedule for the survey and dissemination of the questionnaire were also conducted through the center.

The mental health survey was performed at 18 months ( $\mathrm{SD}=1$ month) after the accident as part of the general health medical examination for the bereaved near the incense altar. Before the survey, researchers obtained informed consent and informed participants of the aim and importance of the study.

\section{Measurement}

Depression was assessed by the Patient Health Questionnaire-9 (PHQ-9), a multipurpose instrument for screening, diagnosing, monitoring and measuring the severity of depression. ${ }^{22}$ The PHQ-9 consists of 9 items and respondents rate the frequency of the symptoms into a scoring severity index from 0 to 3. PHQ-9 scores of 5, 10 and represent mild, moderate, and severe depression. ${ }^{22}$

The PTSD Checklist-5 (PCL-5), a screening instrument for PTSD, was used to screen for current post-traumatic symptoms related to the Sewol ferry accident. The PCL-5 is a 20item self-report measure that assesses the DSM-5 symptoms of PTSD. Each item is rated on a 5-point Likert-type scale that indicates how much the participant has been bothered by the Sewol ferry accident. Preliminary validation work suggests a cutoff score of 38 for PTSD screening and the present study applied the same criteria. ${ }^{23}$

Regarding bereavement, the Inventory of Complicated Grief was used to assess indicators of pathological grief. ${ }^{24}$ The instrument consists of 19 items about immediate bereavementrelated thoughts and behaviors. There are 5 response options ranging from "never" to "always." Participants who score over 25 are considered at high risk for requiring clinical care in this study.

For evaluating embitterment after the disaster, the Post-traumatic Embitterment Disorder (PTED) Self-Rating Scale was used. The PTED self-rating scale is a 19-item questionnaire to evaluate characteristics of an embittered reaction to negative life events. ${ }^{25,26}$ A mean total score $\geq 2.5$ on the PTED scale indicates a clinically significant intensity of reactive embitterment. $^{26}$

Somatic symptom severity was evaluated by the Patient Health Questionnaire-15 (PHQ-15). The PHQ-15 is a 15- item questionnaire comprisedof 15 somatic symptoms. Each symptom is scored from 0 ("not bothered at all") to 2 ("bothered a lot"). PHQ-15 scores of 5, 10, and 15 represent cutoffs for low, medium, and high somatic symptom severity. ${ }^{27}$

The Insomnia Severity Index (ISI) was used as a brief screening measure of insomnia. The ISI is a 7-item questionnaire assessing the nature, severity, and effect of insomnia. A 5 -point Likert scale is used to rate each item (e.g., $0=$ no problem; $4=$ very severe problems), yielding a total score ranging from 0 to 28 . The total score is interpreted as no clinically significant insomnia (0-7), sub-threshold insomnia (8-14), clinically moderate insomnia (15-21) and clinically severe insomnia $(22-28) .^{28,29}$

Alcohol problems were assessed using the Alcohol Use Disorders Identification Test-Alcohol Consumption Questions (AUDIT-C). ${ }^{30,31}$ The AUDIT-C is a 3-item alcohol screen to identify persons who are hazardous drinkers or have an active alcohol use disorder. Responses are rated using a 5-point Likert scale, yielding a total score ranging from 0 to 12 . Total scores can be interpreted as absence of an alcohol problem (0-7) problem drinking (8-10) and alcohol dependence (11-12). ${ }^{32}$

\section{Data analysis}

Univariate descriptive statistics were computed for participants' characteristics (age, gender, marital status, education, income, unemployment after the accident, movement after the accident, existence of remaining children after the accident), psychiatric symptoms (depression, post-traumatic symptoms, complicated grief, embitterment) and other related psychosomatic problems (alcohol problems, sleep and somatic symptoms). The distribution of participants along psychiatric symptom severity was computed using a frequency analysis. Bivariate associations between severity of psychiatric symptoms and other variables were evaluated using regression analysis. Regression analyses after dividing groups by gender were also performed. The present study has three missing values (ICG: 1 case, AUDIT: 1 case, ISI: 1 case). All missing value was replaced by mean substitution methods. All analyses were conducted with SPSS version 21.0 for Windows (SPSS, Inc., an IBM Company, Chicago, IL, USA).

\section{RESULTS}

\section{Characteristics of participants}

The demographics, psychiatric symptoms and other related psychosomatic problems of participants are presented in Table 1.

The mean age of the participants was $47.40( \pm 4.73)$ years and $46.4 \%$ of participants were female. A total of $32 \%$ participants were separated or divorced and mean years of educa- 
Table 1. Characteristics of participants

\begin{tabular}{|c|c|c|c|c|}
\hline Variables & $\mathrm{N}$ & $\%$ & $\mathrm{M}$ & $\mathrm{SD}$ \\
\hline \multicolumn{5}{|l|}{ Demographics variables } \\
\hline Age (years) & & & 47.40 & 4.73 \\
\hline \multicolumn{5}{|l|}{ Sex } \\
\hline Male & 39 & 43 & & \\
\hline Female & 45 & 57 & & \\
\hline \multicolumn{5}{|l|}{ Marital state } \\
\hline Married & 68 & 81.0 & & \\
\hline Single/divorced/separated/widowed & 15 & 17.9 & & \\
\hline Education (yr) & & & 12.43 & 2.11 \\
\hline \multicolumn{5}{|l|}{ Income } \\
\hline Before the accident & & & $3,330,000 \mathrm{KW}$ & 1.64 \\
\hline After the accident & & & $1,740,000 \mathrm{KW}$ & 1.84 \\
\hline Unemployment after the accident & 32 & 38.1 & & \\
\hline Movement after the accident & 14 & 16.7 & & \\
\hline Existence of remaining children after the accident & 74 & 88.1 & & \\
\hline \multicolumn{5}{|c|}{ Psychiatric symptoms and related other psychosomatic problems } \\
\hline Depression (PHQ-9) & & & 18.52 & 5.97 \\
\hline Post traumatic symptoms (PCL) & & & 47.33 & 17.78 \\
\hline Complicated grief (ICG) & & & 52.24 & 14.40 \\
\hline Alcohol problems (AUDIT) & & & 5.12 & 4.25 \\
\hline Sleep (ISI) & & & 13.25 & 6.52 \\
\hline Somatic symptoms (PHQ-15) & & & 14.65 & 6.23 \\
\hline Existence of Past Psychiatric History & 19 & 20 & & \\
\hline
\end{tabular}

PHQ-9: Patient Health Questionnaire-9, ICG: Inventory of Complicated Grief, PCL-5: PTSD Checklist-5, PTED: Post traumatic Embitterment Disorder self rating scale, AUDIT-C: Alcohol Use Disorders Identification Test-Alcohol Consumption Questions, ISI: Insomnia Severity Index, PHQ-15: Patient Health Questionnaire-15

tion were $12.43( \pm 2.11)$. The mean income of the bereaved families decreased from 3,370,000 Korean Won (KW) (approximately US $\$ 3,000$ ) to $1,770,000 \mathrm{KW}$ after the accident. $32 \%$ of participants reported unemployment after the accident and $14 \%$ of them moved out from the home after the accident. $74 \%$ of participants still had remaining children after losing their child due to the accident. 19\% of participants reported a past psychiatric history. To address their mental health problems, participants had visited the Ansan Mental Health Trauma Center (46\%), a counseling service center $(23 \%)$, or a psychiatrist $(21 \%)$. In addition, some participants identified religion (12\%) or talking to their friends $(20 \%)$ as a way of improving their mental health problems.

\section{Psychiatric symptoms and other related psychosomatic problems severity}

The distribution of participants regarding psychiatric symptoms and other related psychosomatic problems severity are summarized in Figure 1. Regarding depression, 50\% of participants suffered from severe depression and $45.2 \%$ and $3.6 \%$ appeared to be moderately and mildly depressed, respectively.
Only $1.2 \%$ of the participants did not report significant depression. Furthermore, $37.6 \%$ of participants reported current suicidal ideation.

In terms of post-traumatic stress, $70.2 \%$ of PCL scores were over 38, which indicated a need for professional intervention and $29.8 \%$ of participants did not report significant posttraumatic stress symptoms.

Regarding complicated grief, ICG scores of almost all participants (94\%) were over 25, categorized as complicated grief. Only $6 \%$ of the participants did not report significant complicated grief.

The mean score of PTED was over 2.5 in $65.5 \%$ of participants, which suggests clinically significant reactive embitterment. A total of $35.5 \%$ did not report significant reactive embitterment.

A total of $50 \%$ of participants suffered from severe somatic symptoms. A total of $27.4 \%$ and $17.9 \%$ of participants reported moderate and mild somatic symptoms, respectively. Regarding sleep problems, $11.9 \%$ of participants reported clinically severe insomnia according to ISI scores. Moderate insomnia was reported in $25 \%$ of participants. A total of $42.9 \%$ 


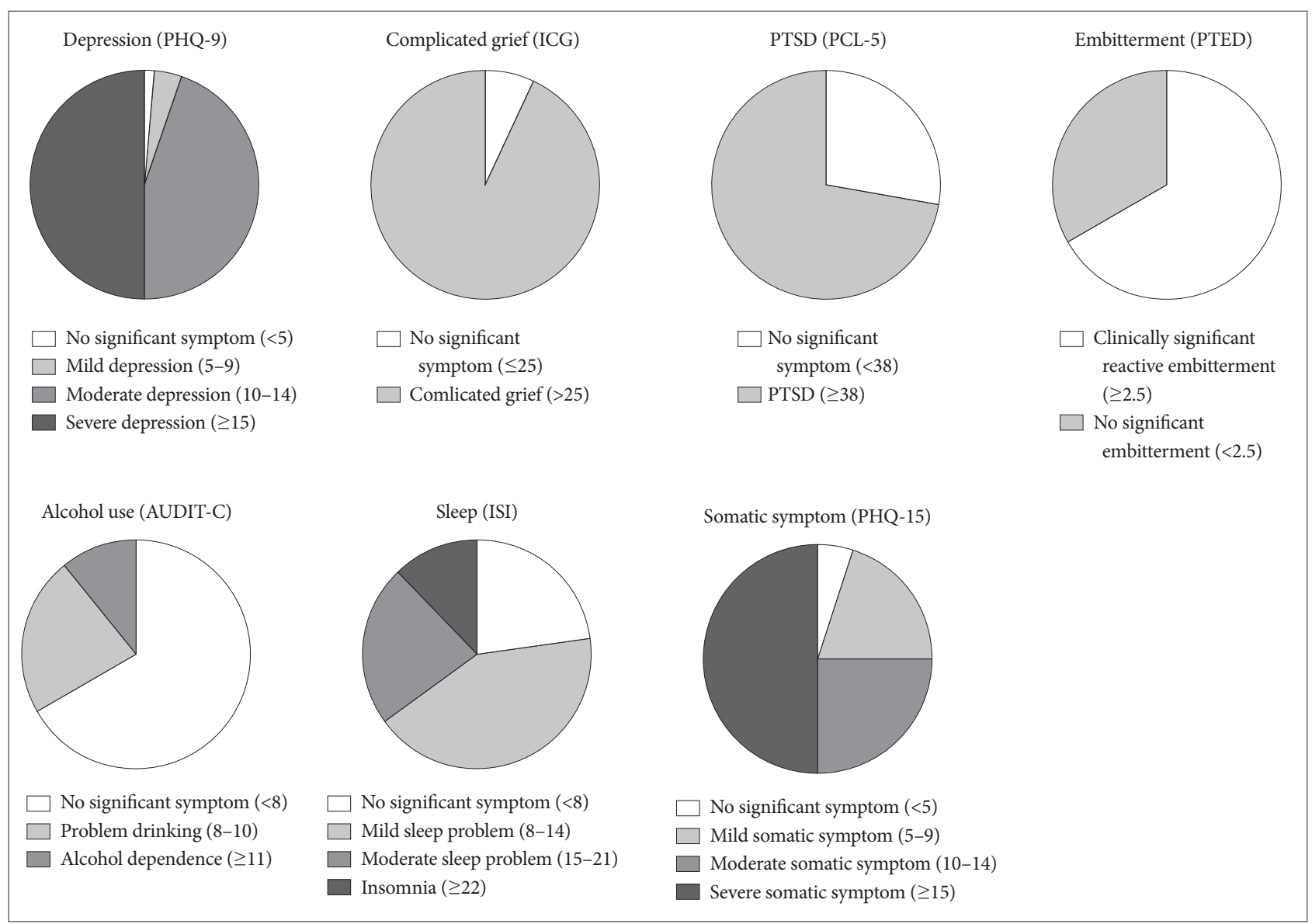

Figure 1. Psychiatric symptoms severity of participants. PHQ-9: Patient Health Questionnaire-9, ICG: Inventory of Complicated Grief, PCL-5: PTSD Checklist-5, PTED: Post traumatic Embitterment Disorder self rating scale, AUDIT-C: Alcohol Use Disorders Identification Test-Alcohol Consumption Questions, ISI: Insomnia Severity Index, PHQ-15: Patient Health Questionnaire-15.

of participants reported sub-threshold insomnia. Regarding alcohol problems, $10.7 \%$ of participants reported alcohol dependence and $25.6 \%$ reported problems with drinking. A total of $63.7 \%$ of participants did not report significant problems with alcohol consumption.

\section{Bivariate association between psychiatric symptoms and other variables}

In a regression analysis for exploring significant predictors of depression, PTSD, and complicated grief, all variables other than education level were not associated with depression, PTSD, and complicated grief in the whole sample (Table 2). Only educational level was associated with the severity of depressive symptoms in participants $(\beta=0.232, \mathrm{p}<0.05)$. In separate analyses by gender, a higher education level was associated with depression $(\beta=0.392, p<0.05)$, complicated grief $(\beta=0.315, p<0.05)$, and PTSD $(\beta=0.382, p<0.05)$ in men, but not in women (Table 3 ). The severity of depression, complicated grief, and PTSD was not significantly different by gender.

\section{DISCUSSION}

The present study aimed to report the overall mental health problems of the bereaved parents during 1.5 years after the Sewol ferry accident. We also aimed to examine gender differences in the grief response. It would be valuable in that the results were from a very homogenous group who experienced the same traumatic event at the same time. Several findings of the study would provide empirical evidence about the negative mental health consequences of the parents whose children were dead by accident.

Most of the bereaved parents appeared to suffer from severe depression, complicated grief, and PTSD in the present study. Results showed that $50 \%$ of the bereaved parents reported severe depression and more than $70 \%$ seemed to suffer from significant post-traumatic symptoms. Furthermore, almost all participants (94\%) met the criteria for complicated grief based on ICG scores. A majority of them (65.5\%) also showed significant reactive embitterment. The prevalence of depression, complicated grief, and PTSD in the present study was much higher than in previous research. The prevalence 
Table 2. Summary of bivariate association between psychiatric symptoms (depression, PTSD and complex grief) and each predictor

\begin{tabular}{|c|c|c|c|c|c|c|c|c|c|}
\hline \multirow{2}{*}{ Variable } & \multicolumn{3}{|c|}{ Depression } & \multicolumn{3}{|c|}{ Complicated grief } & \multicolumn{3}{|c|}{ PTSD } \\
\hline & $\mathrm{B}$ & SE B & $\beta$ & B & SE B & $\beta$ & B & SE B & $\beta$ \\
\hline Age & 0.026 & 0.139 & 0.021 & -0.107 & 0.338 & -0.035 & 0.375 & 0.413 & 0.100 \\
\hline Sex & -1.224 & 1.307 & -0.103 & 3.212 & 3.167 & 0.112 & -1.005 & 3.911 & -0.028 \\
\hline Marital status & -0.380 & 1.717 & -0.025 & -0.907 & 4.155 & -0.024 & -3.029 & 5.107 & -0.066 \\
\hline Education & 0.653 & 0.303 & $0.232^{*}$ & 0.874 & 0.745 & 0.129 & 1.616 & 0.909 & 0.193 \\
\hline Income (before-after) & 0.108 & 0.411 & 0.035 & 0.782 & 0.981 & 0.107 & 1.093 & 1.144 & 0.127 \\
\hline Unemployment after the accident & 0.341 & 1.349 & 0.028 & -3.220 & 3.268 & -0.109 & -6.983 & 3.944 & -0.192 \\
\hline $\begin{array}{l}\text { Existence of remaining children } \\
\text { after the accident }\end{array}$ & 0.405 & 2.365 & 0.019 & 1.611 & 5.660 & 0.032 & -4.199 & 7.075 & -0.067 \\
\hline Past Psychiatric History & 0.889 & 1.594 & 0.061 & 4.020 & 3.833 & 0.116 & 4.313 & 4.732 & 0.100 \\
\hline
\end{tabular}

${ }^{*} \mathrm{p}<0.05$. PTSD: post-traumatic stress disorder

Table 3. Summary of bivariate association between psychiatric symptoms and each predictor (separate analysis by sex)

\begin{tabular}{|c|c|c|c|c|c|c|}
\hline \multirow{3}{*}{ Variable } & \multicolumn{3}{|c|}{ Male } & \multicolumn{3}{|c|}{ Female } \\
\hline & Depression & Complicated grief & PTSD & Depression & Complicated grief & PTSD \\
\hline & \multicolumn{3}{|c|}{$\mathrm{M}(\mathrm{SD})$} & \multicolumn{3}{|c|}{$\mathrm{M}(\mathrm{SD})$} \\
\hline & $19.18(5.87)$ & $50.54(14.71)$ & $47.87(17.80)$ & $17.95(6.06)$ & $53.75(14.11)$ & $46.87(17.80)$ \\
\hline & $\beta$ & & & $\beta$ & & \\
\hline Age & -0.033 & -0.113 & -0.057 & -0.003 & 0.110 & 0.228 \\
\hline Marital status & 0.197 & -0.114 & -0.171 & 0.118 & 0.033 & 0.018 \\
\hline Education & $0.392^{*}$ & $0.315^{*}$ & $0.382^{*}$ & 0.073 & -0.016 & 0.019 \\
\hline Income (before-after) & 0.126 & 0.073 & 0.007 & 0.145 & 0.184 & 0.215 \\
\hline Unemployment after the accident & 0.025 & -0.174 & -0.168 & 0.032 & -0.054 & -0.212 \\
\hline $\begin{array}{l}\text { Existence of remaining children } \\
\text { after the accident }\end{array}$ & 0.112 & 0.193 & 0.062 & -0.091 & -0.141 & -0.210 \\
\hline Past Psychiatric History & -0.171 & -0.191 & -0.119 & 0.023 & 0.073 & 0.085 \\
\hline
\end{tabular}

${ }^{*} \mathrm{p}<0.05$. PTSD: post-traumatic stress disorder

of depression and PTSD typically varies from 10-65\% (depression) and 5-68\% (PTSD) among bereaved populations after a disaster. ${ }^{18,33-36}$ A total of $14-76 \%$ of bereaved people typically suffered from complicated or prolonged grief after a sudden, violent loss. ${ }^{21,37,38}$

Several explanations may be plausible about the severe mental health state of the bereaved parents. First, the Sewol ferry accident was considered to be a large-scale disaster caused by human error, leading to multiple deaths of adolescents. Psychological distress appears to be greater after deaths caused by disasters resulting from human error, such as technical accidents. ${ }^{39}$ People usually perceive that there is someone to blame in such disasters, while natural disasters are regarded as unavoidable. ${ }^{40}$ A previous study of parents who lost sons due to military operation showed that parents view such losses as preventable and expressed anger and bitterness. ${ }^{41}$ The bereaved parents of the Sewol ferry accident seemed to have a similar attitude about the cause of the accident. They thought that the disaster was avoidable and that it was caused by cor- porations and the government. Blaming something or others for such losses can increase mental health problems around grief. ${ }^{42,43}$ Furthermore, underlying anger and embitterment can be major factors that intensify and prolong other psychological distress. The majority of the bereaved parents believed that the disaster was the result of unjustness and unfairness in society. It may be possible that psychological recovery from the disaster may involve 'forgetting' what had been done to them and their children. ${ }^{44}$ This aggression makes moving toward psychological recovery difficult. Further investigation of the role of anger or embitterment in traumatic grief is necessary from a long-term perspective.

Second, the multiple simultaneous deaths of young high school students had received much attention from the media, arousing social and political concern, which consequently caused psychological shock to the entire society. Such publicity might lead to sympathy and support, but it can also cause bereaved parents to involuntarily experience "disaster identity or stigma". The disaster identity or stigma may interrupt nor- 
mal mourning processes and recovery.

The present study also showed that such a loss resulted in a broad range of mental health problems, including insomnia, alcohol use problems, and psychosomatic pain. Intimate relationships have an extensive effect on physical, cognitive, and emotional processes in life. ${ }^{45}$ A previous study suggests that the unexpected death of a loved one may result in a wide range of mental and physical problems across the lifespan. ${ }^{34}$ Insomnia has been often associated with bereavement and several previous studies indicate a relationship between complicated grief symptoms and sleep disturbance in bereaved adults. ${ }^{46-48}$ One previous study reported that the rate of insomnia was higher (22\%) in a bereavement sample than in a non-bereaved control group (17\%). ${ }^{49}$ The present study showed a much higher rate of clinically significant insomnia (39.9\%). The high prevalence rate of this study may result from the traumatic nature of bereavement after the accident. Regarding alcohol problems, 36.3\% of participants appeared to have an alcohol use problem. Several studies have found that severe stressful life events can lead to increased alcohol consumption. $.^{50-52} \mathrm{Be}-$ cause grief involves severe stress, increased alcohol consumption can be expected in bereaved people. ${ }^{53,54}$ Likewise, one previous study about alcohol use and bereavement reported that the rate of men with risky alcohol consumption was $18.4 \%$ for one year and $29.8 \%$ for the two years following the loss. ${ }^{51}$ Further, half of the participants in the present study reported severe physical symptoms. Although few studies have examined the relationship between traumatic loss and psychosomatic symptoms, there is much evidence for a relationship between traumatic experiences and physical health problems and between trauma exposure and medical service utilization. ${ }^{55}$ Furthermore, bereaved people appear to be at high risk for hospitalization and mortality. ${ }^{56} \mathrm{~A}$ previous study about disaster-related loss after 9/11 terrorism found that 9/ 11-related loss was significantly related to severe pain interference and functional impairment. ${ }^{35}$ The previous finding is consistent with the results of the present study, suggesting that response to traumatic loss can extend beyond the emotional level to present as somatic comorbidity. ${ }^{57}$

The present study did not find results regarding sociodemographic factors as in other bereavement studies about disaster-related loss. Although several previous studies about traumatic grief suggest that women generally experience a more severe grief response than men in the initial 2-3 years after loss, no significant differencein overall grief response between mothers and fathers was found in the present study. However, our results may reflect the importance of paying particular attention to long-term mental health changes in fathers for several reasons. First, there is a possibility that losing a child after the Sewol ferry accident provoked relatively more severe mental health problems, especially in fathers, compared to other types of bereavement. In particular, the stronger effect of the accident on fathers than in mothers could elevate the prevalence rate of overall mental health problems in fathers, resulting in no significant difference by gender. Our result is consistent with previous findings that the loss of children appears to be a greater risk factor for complicated grief only in men in relation to other types of bereavement. ${ }^{58}$ One previous study of only bereaved parents, not including other relatives or family, did not find a significant gender effect on grief responses. ${ }^{59}$ Furthermore, based on previous findings suggesting that the depressive symptoms of the bereaved fathers remain unchanged whereas mothers' depression improved over time, it is possible that the mental health problems of fathers of the Sewol ferry accident will remain in a severe state, causing critical results such as suicide or substance abuse for a long time..$^{59}$

In contrast to previous results finding that a low education level is a vulnerable factor for pathologic grief reactions, a greater number of years of education was significantly associated with the severity of depressive symptoms, complicated grief, and post-traumatic symptoms in fathers in our study. One reason may be due to Korean cultural background that intensively favors the education of children. Furthermore, parental psychological attention and material investment converge in education when children are high school students in Korea. Parents with a higher educational level may tend to pay particular attention to and make a greater investment in education for their children in high school. For parents who invested more in their child, the loss of a child could result in a more intense grief response in fathers. However, the association between educational level and mental health state was not found in women. Other factors might have more of an effect on the psychiatric symptoms in mothers.

Generally, most post-traumatic symptoms and grief symptoms decrease as time passes. ${ }^{41,60}$ Although 18 months had passed after the Sewol ferry accident, the parents still experienced severe mental health problems. For this reason, particular clinical attention for parents will be necessary for a long time.

There are several limitations to this study. First, the study includes only a portion of all the bereaved parents due to the difficulty of obtaining consent. Selection bias should be considered because the study was limited only to those who agreed to participate. However, it is also possible that the overall mental status of all bereaved parents has been underestimated if the bereaved parents who did not participate in the study experience more severe psychopathology than the parents participating in the study. The parents who did not participate might have rejected the study because of mistrust and 
anger at the society or they might have difficulty going outside due to severe mental health problems. Second, the present study was cross-sectional in design without a comparison group. It is impossible to establish a causal relationship between trauma-related variables and current mental health. Third, self-report questionnaires are not diagnostic measures and the interpretation of such datais limited.

Despite these limitations, the present study has strengths in that participants are a homogenous group, having experienced the same traumatic event simultaneously and living in the same city with similar socioeconomic backgrounds. Future studies that investigate individual psychological risk and protective factors with homogenous participants who have similar socio-demographic and trauma-related characteristics would provide valuable evidence about traumatic grief. In addition, long-term, follow-up studies are needed to deepen our understating of prognostic factors about traumatic loss.

\section{Acknowledgments}

This study was supported by a grant of the Korean Mental Health Technology R\&D Project, Ministry of Health \& Welfare, Republic of Korea (HM15C1054).

\section{REFERENCES}

1. Kim HS. Ansan Mental Health Trauma Center 2014 Activity Report. Ansan, Gyungi-Do: Ansan Mental Health Trauma Center; 2014.

2. Kim JH. Sewol's Cause of Accident 'Sudden Turn' is Concluded to be the Cause. Seoul: Kyunghyang Shinmun; 2014.

3. Charlie C. Reports: The South Korean Ferry Sank because it was Dangerously Overloaded. New York: Time; 2014.

4. McCurry J. South Korea Ferry Verdict: Sewol Captain Sentenced to 36 years in Prison. London: The Guardian; 2014.

5. Jethor M, Stella K. South Korea Cracking Down on Cooperator in Sewol Ferry Disaster, CEO Arrested. Atlanta: CNN; 2014.

6. Choe SH. South Korea's Leader and Media Face Scrutiny over Ferry Disaster. New York: The New York Times; 2014.

7. Cho CU. 'Sewol Disaster Reveals Failure of Mass Media as Watchdog.' Seoul: The Korea Herald; 2014.

8. Yu SH. "MV Sewol 'All Students Rescued' First Misreport Mad by MBC"... Why? Seoul: Oh My News; 2014.

9. Nam IS. Media Outlets Apologize over Sewol Ferry Disaster Coverage. New York: The Wall Street Journal; 2014.

10. Choe SH, Lee SH, Ham JH. Human Error Suspected as Hope Fades in Korean Ferry Sinking. Seoul: The New York Times; 2014.

11. Elise A. South Korea Sewol Ferry Disaster: Protests Continue in Seoul, Thousands March to Fight Government Corruption. New York: International Business Times; 2015.

12. Park M, Hancocks P. Sweol Ferry Disaster: One Year on, Grieving Families Demand Answers. Atlanta: CNN; 2015.

13. Fackler M. A Year after Sewol Ferry Tragedy, Peace is Elusive for South Korean City. New York: The New York Times; 2015.

14. Mills MA, Edmondson D, Park CL. Trauma and stress response among Hurricane Katrina evacuees. Am J Public Health 2007;97(Suppl 1):S116-S123.

15. Herman D, Felton C, Susser E. Mental health needs in New York state following the September 11th attacks. J Urban Health 2002;79:322-331.

16. North CS, Nixon SJ, Shariat S, Mallonee S, McMillen JC, Spitznagel EL, et al. Psychiatric disorders among survivors of the Oklahoma City bombing. JAMA 1999;282:755-762.
17. Goenjian AK, Steinberg AM, Najarian LM, Fairbanks LA, Tashjian M, Pynoos RS. Prospective study of posttraumatic stress, anxiety, and depressive reactions after earthquake and political violence. Am J Psychiatry 2000;157:911-916.

18. Bonanno GA, Kaltman S. Toward an integrative perspective on bereavement. Psychol Bull 1999;125:760-776.

19. Kaltman S, Bonanno GA. Trauma and bereavement: examining the impact of sudden and violent deaths. J Anxiety Disord 2003;17:131-147.

20. Bonanno GA, Neria Y, Mancini A, Coifman KG, Litz B, Insel B. Is there more to complicated grief than depression and posttraumatic stress disorder? A test of incremental validity. J Abnorm Psychol 2007;116: 342-351.

21. Neria Y, Gross R, Litz B, Maguen S, Insel B, Seirmarco G, et al. Prevalence and psychological correlates of complicated grief among bereaved adults 2.5-3.5 years after September 11th attacks. J Trauma Stress 2007;20:251-262.

22. Kroenke K, Spitzer RL, Williams JB. The PHQ-9: validity of a brief depression severity measure. J Gen Intern Med 2001;16:606-613.

23. Hoge CW, Riviere LA, Wilk JE, Herrell RK, Weathers FW. The prevalence of post-traumatic stress disorder (PTSD) in US combat soldiers: a head-to-head comparison of DSM-5 versus DSM-IV-TR symptom criteria with the PTSD checklist. Lancet Psychiatry 2014;1:269-277.

24. Prigerson HG, Maciejewski PK, Reynolds CF 3rd, Bierhals AJ, Newsom JT, Fasiczka A, et al. Inventory of Complicated Grief: a scale to measure maladaptive symptoms of loss. Psychiatry Res 1995;59:65-79.

25. Shin C, Han C, Linden M, Chae JH, Ko YH, Kim YK, et al. Standardization of the korean version of the posttraumatic embitterment disorder self-rating scale. Psychiatry Investig 2012;9:368-372.

26. Linden M, Baumann K, Lieberei B, Rotter M. The Post-Traumatic Embitterment Disorder Self-Rating Scale (PTED Scale). Clin Psychol Psychother 2009;16:139-147.

27. Kroenke K, Spitzer RL, Williams JB. The PHQ-15: validity of a new measure for evaluating the severity of somatic symptoms. Psychosom Med 2002;64:258-266.

28. Bastien CH, Vallieres A, Morin CM. Validation of the Insomnia Severity Index as an outcome measure for insomnia research. Sleep Med 2001; 2:297-307.

29. Morin CM, Belleville G, Bélanger L, Ivers H. The Insomnia Severity Index: psychometric indicators to detect insomnia cases and evaluate treatment response. Sleep 2011;34:601-608.

30. Bush K, Kivlahan DR, McDonell MB, Fihn SD, Bradley KA. The AUDIT alcohol consumption questions (AUDIT-C): an effective brief screening test for problem drinking. Ambulatory Care Quality Improvement Project (ACQUIP). Alcohol Use Disorders Identification Test. Arch Intern Med 1998;158:1789-1795.

31. Bradley KA, Bush KR, Epler AJ, Dobie DJ, Davis TM, Sporleder JL, et al. Two brief alcohol-screening tests From the Alcohol Use Disorders Identification Test (AUDIT): validation in a female Veterans Affairs patient population. Arch Intern Med 2003;163:821-829.

32. Seong JH, Lee CH, Do HJ, Oh SW, Lym YL, Choi JK, et al. Performance of the AUDIT Alcohol Consumption Questions (AUDIT-C) and AUDIT-K Question 3 Alone in Screening for Problem Drinking. Korean J Fam Med 2009;30:695-702.

33. Kristensen P, Weisaeth L, Heir T. Psychiatric disorders among disaster bereaved: an interview study of individuals directly or not directly exposed to the 2004 tsunami. Depress Anxiety 2009;26:1127-1133.

34. Kuo CJ, Tang HS, Tsay CJ, Lin SK, Hu WH, Chen CC. Prevalence of psychiatric disorders among bereaved survivors of a disastrous earthquake in Taiwan. Psychiatr Serv 2003;54:249-251.

35. Neria Y, Olfson M, Gameroff MJ, Wickramaratne P, Gross R, Pilowsky DJ, et al. The mental health consequences of disaster-related loss: findings from primary care one year after the $9 / 11$ terrorist attacks. Psychiatry 2008;71:339-348.

36. Pfeffer CR, Altemus M, Heo M, Jiang H. Salivary cortisol and psychopathology in adults bereaved by the September 11, 2001 terror attacks. 
Int J Psychiatry Med 2009;39:215-226.

37. Ginzburg K, Geron Y, Solomon Z. Patterns of complicated grief among bereaved parents. Omega J Death Dying 2002;45:119-132.

38. Morina N, Rudari V, Bleichhardt G, Prigerson HG. Prolonged grief disorder, depression, and posttraumatic stress disorder among bereaved Kosovar civilian war survivors: a preliminary investigation. Int J Soc Psychiatry 2010;56:288-297.

39. Norris FH, Friedman MJ, Watson PJ, Byrne CM, Diaz E, Kaniasty K. 60,000 disaster victims speak: Part I. An empirical review of the empirical literature, 1981-2001. Psychiatry 2002;65:207-239.

40. Weisœth L. Collective Traumatic Stress: Crisis and Catastrophes. Stress in Health and Disease. Weinheim: Wiley-VCH Veriag GmbH \& Co KGaA, 2006;71-91.

41. Kristensen P, Heir T, Herlofsen PH, Langsrud O, Weisaeth L. Parental mental health after the accidental death of a son during military service: 23-year follow-up study. J Nerv Ment Dis 2012;200:63-68.

42. Brent D, Melhem N, Donohoe MB, Walker M. The incidence and course of depression in bereaved youth 21 months after the loss of a parent to suicide, accident, or sudden natural death. Am J Psychiatry 2009; 166:786-794.

43. Melhem NM, Moritz G, Walker M, Shear MK, Brent D. Phenomenology and correlates of complicated grief in children and adolescents. J Am Acad Child Adolesc Psychiatry 2007;46:493-499.

44. Linden M. Posttraumatic embitterment disorder. Psychother Psychosom 2003;72:195-202.

45. Waters E, Cummings EM. A secure base from which to explore close relationships. Child Dev 2000;71:164-172.

46. Prigerson HG, Frank E, Kasl SV, Reynolds CF 3rd, Anderson B, Zubenko GS, et al. Complicated grief and bereavement-related depression as distinct disorders: preliminary empirical validation in elderly bereaved spouses. Am J Psychiatry 1995;152:22-30.

47. McDermott OD, Prigerson HG, Reynolds CF 3rd, Houck PR, Dew MA, Hall M, et al. Sleep in the wake of complicated grief symptoms: an exploratory study. Biol Psychiatry 1997;41:710-716.

48. Martin JL. Psychological consequences of AIDS-related bereavement among gay men. J Consult ClinPsychol 1988;56:856-862.
49. Hardison HG, Neimeyer RA, Lichstein KL. Insomnia and complicated grief symptoms in bereaved college students. Behav Sleep Med 2005; 3:99-111.

50. Keyes KM, Pratt C, Galea S, McLaughlin KA, Koenen KC, Shear MK. The burden of loss: unexpected death of a loved one and psychiatric disorders across the life course in a national study. Am J Psychiatry 2014;171:864-871.

51. Pilling J, Thege BK, Demetrovics Z, Kopp MS. Alcohol use in the first three years of bereavement: a national representative survey. Subst Abuse Treat Prev Policy 2012;7:3.

52. Dawson DA, Grant BF, Ruan WJ. The association between stress and drinking: modifying effects of gender and vulnerability. Alcohol Alcohol 2005;40:453-460.

53. Chen JH, Bierhals AJ, Prigerson HG, Kasl SV, Mazure CM, Jacobs S. Gender differences in the effects of bereavement-related psychological distress in health outcomes. Psychol Med 1999;29:367-380.

54. Stroebe M, Schut H, Stroebe W. Health outcomes of bereavement. Lancet 2007;370:1960-1973.

55. Elhai JD, North TC, Frueh BC. Health service use predictors among trauma survivors: a critical review. Psychol Serv 2005;2:3-19.

56. Li J, Laursen TM, Precht DH, Olsen J, Mortensen PB. Hospitalization for mental illness among parents after the death of a child. N Engl J Med 2005;352:1190-1196.

57. Prigerson HG, Bierhals AJ, Kasl SV, Reynolds CF 3rd, Shear MK, Day $\mathrm{N}$, et al. Traumatic grief as a risk factor for mental and physical morbidity. Am J Psychiatry 1997;154:616-623.

58. Johannesson KB, Lundin T, Hultman CM, Frojd T, Michel PO. Prolonged grief among traumatically bereaved relatives exposed and not exposed to a tsunami. J Trauma Stress 2011;24:456-464.

59. Liu W, Fan F, Liu J. Depressive symptoms in bereaved parents in the 2008 Wenchuan, China earthquake: a cohort study. J Trauma Stress 2013;26:274-279.

60. Murphy SA, Johnson LC, Chung IJ, Beaton RD. The prevalence of PTSD following the violent death of a child and predictors of change 5 years later. J Trauma Stress 2003;16:17-25. 